\title{
Characteristics, Management, and Clinical Outcomes of Patients with Hospital-Acquired and Ventilator-Associated Pneumonia: A Multicenter Cohort Study in Korea
}

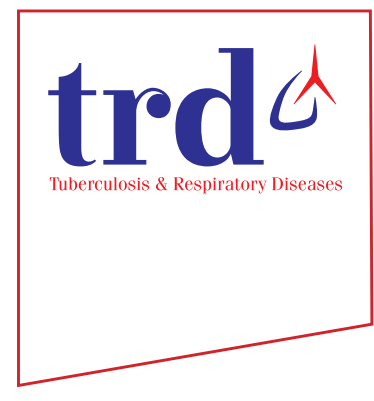

Ryoung-Eun Ko, M.D., Ph.D. ${ }^{1 *}{ }^{\mathbb{1}}$, Kyung Hoon Min, M.D., Ph.D. ${ }^{2, * \mathbb{E}}$, Sang-Bum Hong, M.D., Ph.D. ${ }^{3}$, Ae-Rin Baek, M.D., Ph.D. ${ }^{4}$, Hyun-Kyung Lee, M.D., Ph.D. ${ }^{5}$, Woo Hyun Cho, M.D., Ph.D. ${ }^{6}$, Changhwan Kim, M.D., Ph.D. ${ }^{7}$, Youjin Chang, M.D., Ph.D. ${ }^{8}$, Sung-Soon Lee, M.D., Ph.D. ${ }^{9}$, Jee Youn Oh, M.D., Ph.D. ${ }^{2}$, Heung Bum Lee, M.D., Ph.D. ${ }^{10}$, Soohyun Bae, M.D., Ph.D. ${ }^{11, \dagger}$, Jae Young Moon, M.D., Ph.D. ${ }^{12,}$, Kwang Ha Yoo, M.D., Ph.D. ${ }^{13}$, Kyeongman Jeon, M.D., Ph.D. ${ }^{1,14} \mathbb{E}$, on behalf of the Korean HAP/VAP Study Group

Author affiliations appear at the end of this article.

Background: Hospital-acquired pneumonia (HAP) and ventilator-associated pneumonia (VAP) are significant public health issues in the world, but the epidemiological data pertaining to HAP/VAP is limited in Korea. The objective of this study was to investigate the characteristics, management, and clinical outcomes of HAP/VAP in Korea.

Methods: This study is a multicenter retrospective cohort study. In total, 206,372 adult patients, who were hospitalized at one of the 13 participating tertiary hospitals in Korea, were screened for eligibility during the six-month study period. Among them, we included patients who were diagnosed with HAP/VAP based on the Infectious Diseases Society of America (IDSA)/American Thoracic Society (ATS) definition for HAP/VAP.

Results: Using the IDSA/ATS diagnostic criteria, 526 patients were identified as HAP/VAP patients. Among them, 27.9\% were diagnosed at the intensive care unit (ICU). The cohort of patients had a median age of 71.0 (range from 62.0 to 79.0) years. Most of the patients had a high risk of aspiration (63.3\%). The pathogen involved was identified in 211 patients (40.1\%). Furthermore, multidrug resistant (MDR) pathogens were isolated in 138 patients; the most common MDR pathogen was Acinetobacter baumannii. During hospitalization, 107 patients with HAP (28.2\%) had to be admitted to the ICU for additional care. The hospital mortality rate was $28.1 \%$ in the cohort of this study. Among the 378 patients who survived, $54.2 \%$ were discharged and sent back home, while $45.8 \%$ were transferred to other hospitals or facilities.

Address for correspondence: Kyeongman Jeon, M.D., Ph.D.

Department of Critical Care Medicine and Division of Pulmonary and Critical Care Medicine, Department of Medicine, Samsung Medical Center, Sungkyunkwan University School of Medicine, 81 Irwon-ro, Gangnam-gu, Seoul 06351, Republic of Korea

Phone: 82-2-3410-2423, Fax: 82-2-3410-3849, E-mail: kjeon@skku.edu

*Ryoung-Eun Ko and Kyung Hoon Min contributed equally to this work.

${ }^{\dagger}$ Present address: Department of Integrated Internal Medicine, Myoungji Hospital, Goyang, Republic of Korea

†Present address: Division of Pulmonary and Critical Care Medicine, Department of Internal Medicine, Chungnam National University Sejong Hospital, Sejong, Republic of Korea

Received: Jan. 25, 2021, Revised: Apr. 14, 2021, Accepted: Jun. 2, 2021, Published online: Jun. 4, 2021

@(c) it is identical to the Creative Commons Attribution Non-Commercial License (http://creativecommons.org/licenses/by-nc/4.0/) 
Conclusion: This study found that the prevalence of HAP/VAP in adult hospitalized patients in Korea was 2.54/1,000 patients. In tertiary hospitals in Korea, patients with HAP/VAP were elderly and had a risk of aspiration, so they were often referred to step-down centers.

Keywords: Healthcare-Associated Pneumonia; Ventilator-Associated Pneumonia; Epidemiology; Mortality; Korea

\section{Introduction}

Hospital-acquired pneumonia (HAP) is defined as the development of parenchymal lung infection in hospitalized patients after at least 48-hour post-admission. However, if patients who experience intubation to receive mechanical ventilation (MV) in an intensive care unit (ICU) and then these patients develop parenchymal lung infection within 48 hours of admission, the condition is known as ventilator-associated pneumonia (VAP) ${ }^{1}$. Furthermore, HAP/VAP is the most common nosocomial infection that causes significant clinical and economic burden, including prolonged hospitalization, higher overall health care costs, and increased morbidity and mortal$i^{2-7}$. Previous epidemiological studies have been carried out at a worldwide level. These studies have reported the prevalence of HAP as 5-20 cases per 1,000 hospital admissions and 2.4-6.1 cases per 1,000 non-ICU patients ${ }^{6-11}$. However, the epidemiological data of HAP remains limited in Korea.

Several international organizations have provided guidelines for the appropriate management of HAP/VAP in patients $^{2,3}$. According to these guidelines, physicians should provide an empirical treatment only after considering the local epidemiological findings, etiology, and resistance patterns.

Epidemiological and microbiological information is very important in the management of HAP/VAP, but hospitals in Korea have published very little data about HAP/VAP patients. Therefore, in this study, we investigated the prevalence and underlying characteristics of HAP/VAP in Korean hospitals, which included microbiological information, epidemiology, and the outcomes of HAP/VAP in Korea.

\section{Materials and Methods}

\section{Study design and population}

A nationwide, multicenter retrospective cohort study was conducted by the Korean HAP/VAP Study Group. In this study, 13 tertiary or university-affiliated hospitals of Korea participated. The study protocol was developed by the steering committee, which periodically reviewed the progress of the study and provided an overall supervision of the research study. The study was approved by the institutional review boards of each participating hospital and Samsung Medical Center (No. 2020-03-150). They waived the compulsion of getting an informed consent letter as it was an observational study. In addition, patient information was anonymized and eliminated from records or files prior to analysis.

In this study, the inclusion criteria of patients was follows: (1) they were admitted to the participating hospital for more than three days (from June 1 to December 31, 2019), (2) they were labeled as pneumonia-related International Classification of Diseases-10 code (J13-J18, J85) at discharge, and (3) they were at least 19 years of age. All these patients were screened for eligibility. After performing a comprehensive review of medical records, patients were diagnosed with HAP/ VAP based on the definition ${ }^{1}$ provided by the following organizations: the American Thoracic Society and the Infectious Diseases Society of America (HAP/VAP is a condition that includes new or progressive parenchymal lung infiltrate and clinical findings that suggest infection, e.g., the new onset of fever, purulent sputum, leukocytosis, and a decline in oxygenation). Such patients were included in the study and followed up until their date of death or hospital discharge. In this study, the exclusion criteria of patients was as follows: patients who had received antibiotics for more than 72 hours at other hospitals or who had developed pneumonia within $48 \mathrm{~h}$ of their transfer to another hospital.

\section{Data collection}

In each participating hospital, the trained study coordinators reviewed the electronic medical records of each patient, and they collected the data by using a standardized case report form. The information collected was as follows: (1) the demographic data, including age, sex, comorbidities, and clinical frailty score; (2) the data on HAP/VAP, including risk factors, disease severity, Sequential Organ Failure Assessment (SOFA) scores, laboratory variables, infectious pathogens, and multidrug resistant (MDR) pathogens; (3) the treatment data, including the adequacy of an empirical antibiotic therapy, the adjunctive use of steroids, ICU admissions, and limitations of care decision; and (4) clinical outcomes, including clinical and microbiological responses, in-hospital mortality, and the discharge destination of patients who survived and were discharged. In case of patients admitted to the ICU for HAP/VAP, 
the study coordinators also collected data pertaining to the use of resources and the occurrence of medical events during their stay in the ICU. All the participating hospitals were asked to complete data entries and email the data to the coordination center, where the quality of the data was assessed for completeness and for logical errors.

\section{Definitions}

An infection can be classified into three categories: (1) microbiologically documented infections, (2) clinically documented infections, and (3) possible infections. Cultured pathogens are defined as the microorganisms collected within 2 days of antibiotic treatment by the managing physicians; however, these microorganisms should not be colonizers or contaminants. Furthermore, MDR pathogens are defined as the microorganisms that are resistant to agents of three or more antimicrobial categories ${ }^{12}$. An initial antimicrobial therapy was provided in the absence of microbiological isolates, and was considered to be an empirical therapy. Based on the results of drug susceptibility testing, we gauged the adequacy of this empirical therapy. The baseline SOFA score was assumed to be zero in patients who did not have a pre-existing organ dysfunction ${ }^{13,14}$. The risks of aspiration were classified as follows: (1) an impaired swallowing (esophageal disease, neurological disease, or recent extubation), (2) an impaired consciousness, (3) an increased chance of gastric contents reaching the lung (reflux or tube feeding), and (4) an impaired cough reflex (medications, stroke, or dementia) $)^{15}$. Sepsis and septic shock were defined by the clinical criteria presented in the 3rd International Consensus Definitions for Sepsis and Septic Shock (Sepsis-3) ${ }^{16}$.

Clinical responses were classified according to the following three categories: (1) clinical cure (an improvement in all the signs and symptoms of pneumonia), (2) clinical failure (the persistence or worsening of signs, symptoms, or both of pneumonia; the symptoms or signs of pneumonia, or both, occurred within 3 days after the termination of medical treatment), and (3) the recurrence of pneumonia (the occurrence of a new event of pneumonia 72 hours after the discontinuation of antibiotics). In addition, microbiological responses were classified as follows: (1) microbiological eradication: an absence of the baseline pathogen in the final culture of specimens during hospitalization, (2) colonization: persistence of the baseline pathogen but clinically cured, (3) microbiological failure: persistence of the baseline pathogen with clinical failure, and (4) microbiological recurrence: regrowth of the baseline pathogen irrespective of the clinical outcome.
Table 1. Baseline characteristics of patients with hospitalacquired and ventilator-associated pneumonia

\begin{tabular}{|lc|}
\hline \multicolumn{1}{|c|}{ Variable } & Value (n=526) \\
\hline Age, yr & $71.0(62.0-79.0)$ \\
Male sex & $360(68.4)$ \\
\hline Body mass index, kg/m & $21.9(19.4-24.5)$ \\
Comorbidity & \\
\hline Diabetes & $167(31.7)$ \\
\hline Cardiovascular disease & $107(20.3)$ \\
\hline Chronic lung disease & $77(14.6)$ \\
\hline Chronic neurological disease & $147(27.9)$ \\
\hline Chronic kidney disease & $77(14.6)$ \\
\hline Chronic liver disease & $40(7.6)$ \\
\hline Connective tissue disease & $16(3.0)$ \\
\hline Immunocompromised & $29(5.5)$ \\
\hline Hematological malignancy & $41(7.8)$ \\
\hline Solid malignant tumor & $189(35.9)$ \\
\hline High dose or long-term steroid use & $36(6.8)$ \\
\hline Charlson Comorbidity Index & $5.0(3.0-6.0)$ \\
\hline Clinical Frailty Scale & $5.0(3.0-7.0)$ \\
\hline Reason for admission & $13(2.5)$ \\
\hline Medical & $52(9.9)$ \\
\hline Medical disease treatment & \\
\hline Diagnostic work-up & \\
\hline Surgical & \\
\hline Elective operation & \\
\hline Emergency operation & $(57.6)$ \\
\hline Other reasons than operation & \\
\hline
\end{tabular}

Values are presented as median (interquartile range) or number (\%)

\section{Results}

\section{Study population}

The study was conducted for a period of 6 months, which extended from June 1 to December 31, 2019. During this period, 206,372 adult patients were admitted into the participating hospitals; however, only 526 patients were diagnosed with HAP/VAP (2.54/1,000 patients). Table 1 enlists the baseline characteristics of these patients: there were 360 male patients (68.4\%), and 166 female patients (31.6\%) with HAP/VAP; the median age of these patients was 71.0 years (range, 62.0-79.0 years). The most common comorbidities were as follows: solid malignant tumors (35.9\%), diabetes (31.7\%), and chronic neurological disease (27.9\%). The median Charlson Comorbidity Index was 5.0 (3.0-6.0) and the Clinical Frailty Scale was 5.0 
Table 2. Clinical characteristics on the day of diagnosis of hospital-acquired and ventilator-associated pneumonia

\begin{tabular}{|c|c|}
\hline Variable & Value $(n=526)$ \\
\hline \multicolumn{2}{|l|}{ Classification of pneumonia } \\
\hline Hospital-acquired pneumonia & $419(79.7)$ \\
\hline Ventilator-associated pneumonia & $107(20.3)$ \\
\hline \multicolumn{2}{|l|}{ Location of diagnosis } \\
\hline General ward & $379(72.1)$ \\
\hline Intensive care unit & $147(27.9)$ \\
\hline \multicolumn{2}{|l|}{ Prior IV antibiotic use within 90 days } \\
\hline Used & $381(72.4)$ \\
\hline Not used & $141(26.8)$ \\
\hline No data & $4(0.8)$ \\
\hline \multicolumn{2}{|l|}{ Artificial airway } \\
\hline None & $377(71.7)$ \\
\hline Endotracheal tube & $104(19.8)$ \\
\hline Tracheostomy & $42(8.0)$ \\
\hline Other & $3(0.6)$ \\
\hline Risk of aspiration & $333(63.3)$ \\
\hline Impaired swallowing & 223 \\
\hline Impaired consciousness & 171 \\
\hline $\begin{array}{l}\text { Increased chance of gastric contents } \\
\text { reaching the lung }\end{array}$ & 202 \\
\hline Impaired cough reflex & 156 \\
\hline SOFA score & $4.0(2.0-7.0)$ \\
\hline Sepsis & $336(63.9)$ \\
\hline Septic shock & $56(10.6)$ \\
\hline \multicolumn{2}{|l|}{ Specimen for bacterial cultures } \\
\hline Respiratory samples & $434(82.5)$ \\
\hline Sputum & $287(54.6)$ \\
\hline Transtracheal aspirates & $168(31.9)$ \\
\hline Bronchial washing fluid & $34(6.5)$ \\
\hline Bronchoalveolar lavage & $9(1.7)$ \\
\hline Blood & $417(79.3)$ \\
\hline Pleural fluid & $32(6.1)$ \\
\hline Serological test for atypical pathogen & $92(17.5)$ \\
\hline Respiratory virus test & $130(24.7)$ \\
\hline AFB stain and culture & $163(31.0)$ \\
\hline \multicolumn{2}{|l|}{ Laboratory test } \\
\hline White blood cell, $\times 10^{3} / \mathrm{L}$ & $10.2(7.1-14.5)$ \\
\hline Hemoglobin, g/dL & $10.0(8.8-11.5)$ \\
\hline Platelet count, $\times 10^{3} / \mathrm{L}$ & $175.0(95.0-252.0)$ \\
\hline Sodium, $\mathrm{mmol} / \mathrm{L}$ & $137.0(133.0-140.0)$ \\
\hline Chloride, $\mathrm{mmol} / \mathrm{L}$ & $101.0(98.0-105.0)$ \\
\hline
\end{tabular}

Table 2. Continued

\begin{tabular}{|lc|}
\hline \multicolumn{1}{|c|}{ Variable } & Value $(\mathbf{n = 5 2 6})$ \\
\hline Creatinine, $\mathrm{mg} / \mathrm{dL}$ & $0.8(0.6-1.3)$ \\
AST, $\mathrm{U} / \mathrm{L}$ & $29.0(20.0-47.0)$ \\
ALT, U/L & $21.0(13.0-37.0)$ \\
Albumin, g/dL & $2.9(2.6-3.2)$ \\
INR & $1.2(1.1-1.2)$ \\
C-reactive $\mathrm{protein}, \mathrm{mg} / \mathrm{dL}$ & $10.4(6.1-17.9)$ \\
Procalcitonin, $\mathrm{mmol} / \mathrm{L}$ & $0.4(0.4-0.4)$ \\
Lactate, $\mathrm{mmol} / \mathrm{L}$ & $1.4(1.3-1.7)$ \\
Glucose, $\mathrm{mg} / \mathrm{dL}$ & $133.5(111.0-161.0)$ \\
\hline
\end{tabular}

Values are presented as number (\%) or median (interquartile range).

IV: intravenous; SOFA: Sequential Organ Failure Assessment; AFB: acid-fast bacilli; AST: aspartate aminotransferase; ALT: alanine aminotransferase; INR: international normalized ratio.

(3.0-7.0). The most common reasons for hospitalization were treatment of medical diseases ( $\mathrm{n}=303,57.6 \%)$, followed by elective operation ( $\mathrm{n}=106,20.2 \%)$.

\section{Clinical characteristics on the day of HAP/VAP diagnosis}

In this study, HAP was diagnosed in 419 patients (79.7\%) (379 patients in general ward and 40 patients in the ICU), whereas VAP was diagnosed in 107 (20.3\%) patients (Table 2). Among the 526 patients, 381 patients (71.4\%) were administered intravenous antibiotics for 90 days, and 149 patients (28.3\%) were provided with artificial airways. A vast majority of patients ( $\mathrm{n}=333,63.3 \%$ ) had at least one aspiration risk: the most common risk was impaired swallowing $(\mathrm{n}=223,42.4 \%)$, followed by cases having an increased likelihood of retrograde gastric content flow to the lung $(\mathrm{n}=202,38.4 \%)$. The median SOFA score was $4.0(2.0-7.0)$. Sepsis was observed in 336 (63.9\%) of the total patients, and septic shock was observed in 56 patients $(10.6 \%)$.

\section{Diagnostic materials and microbiology}

During the evaluation of pathogens, we found the highest number of analyzed specimens in blood cultures (79.3\%), sputum (54.6\%), and transtracheal aspirations (31.9\%). Moreover, 99 patients (18.8\%) had colonized pathogens before being diagnosed with HAP/VAP. The median value of C-reactive protein was $10.4 \mathrm{mg} / \mathrm{dL}$ (range, $6.1-17.9 \mathrm{mg} / \mathrm{dL}$ ), and the median value of procalcitonin was $0.4 \mathrm{mmol} / \mathrm{L}$ (range, $0.4-0.4$ $\mathrm{mmol} / \mathrm{L}$ ), respectively.

The pathogen involved was identified in 211 patients (40.1\%) (Table 3). The most common specimens in which 
Table 3. Bacterial pathogen identified in patients with hospital-acquired and ventilator-associated pneumonia

\begin{tabular}{|c|c|}
\hline Variable & $\begin{array}{c}\text { No. } \\
(n=211)\end{array}$ \\
\hline \multicolumn{2}{|l|}{ Gram-positive pathogens } \\
\hline Staphylococcus aureus & 24 \\
\hline Streptococcus pneumonia & 7 \\
\hline Enterococcus faecium & 5 \\
\hline $\begin{array}{l}\text { Nonstaphylococcus aureus } \\
\text { Staphylococcus species }\end{array}$ & 4 \\
\hline Others* & 5 \\
\hline \multicolumn{2}{|l|}{ Gram-negative pathogens } \\
\hline Acinetobacter baumannii & 68 \\
\hline Pseudomonas aeruginosa & 36 \\
\hline Klebsiella pneumoniae & 35 \\
\hline Escherichia coli & 11 \\
\hline Sternotrophomonas maltophilia & 11 \\
\hline Enterobacter cloacae & 10 \\
\hline Serratia marcescens & 5 \\
\hline Proteus species & 4 \\
\hline Klebsiella aerogenes & 3 \\
\hline Moraxella catarrhalis & 2 \\
\hline Burkholderia cephacia & 2 \\
\hline Citrobacter species & 2 \\
\hline Others $^{\dagger}$ & 2 \\
\hline MDR pathogen identified ${ }^{\ddagger}, \mathrm{n}(\%)$ & $138(70.4)$ \\
\hline Acinetobacterspecies & 67 \\
\hline Pseudomonas aeruginosa & 30 \\
\hline Enterobacteriaceae & 27 \\
\hline Staphylococcus aureus & 19 \\
\hline Enterococcus species & 4 \\
\hline
\end{tabular}

*Others included one Streptococcus pyogenes, one Streptococcus mitis, one Streptococcus agalactiae, one Streptococcus angiosus, and one Listeria monocytogenes. ${ }^{\dagger}$ Others included one Klebsiella oxytoca and one Raoultella planticola. ${ }^{*}$ Data were available for 196 patients.

MDR: multidrug resistance.

the pathogens were identified to be involved were respiratory specimens $(\mathrm{n}=189,89.5 \%)$; bacteremia was detected in 22 cases (10.4\%). The most common pathogens were Acinetobacter baumannii ( $\mathrm{n}=68)$, followed by Pseudomonas aeruginosa $(\mathrm{n}=36)$, Klebsiella pneumonia $(\mathrm{n}=35)$, and Staphylococcus aureus $(\mathrm{n}=24)$. Moreover, MDR pathogens caused infection in 138 patients $(70.4 \%)$, which had microbiologically diagnosed HAP/VAP. Furthermore, Acinetobacter species accounted for approximately half of the MDR pathogens, followed by Pseu-
Table 4. Treatment for hospital-acquired and ventilatorassociated pneumonia

\begin{tabular}{|c|c|}
\hline Variable & Value $(n=526)$ \\
\hline \multicolumn{2}{|l|}{ Initial empirical antibiotics } \\
\hline $\begin{array}{l}\text { Extended-spectrum penicillin/ } \\
\text { beta-lactamase inhibitor }\end{array}$ & $312(59.3)$ \\
\hline Respiratory fluoroquinolone & $169(32.1)$ \\
\hline Third cephalosporin & $53(10.1)$ \\
\hline Cefepime & $35(6.7)$ \\
\hline Aminoglycoside & $13(2.5)$ \\
\hline Glycopeptide & $79(15.0)$ \\
\hline Carbapenem & $107(20.3)$ \\
\hline Colistin & $8(1.5)$ \\
\hline Marcrolide & $5(1.0)$ \\
\hline Others & $44(8.4)$ \\
\hline Combination therapy of empirical antibiotics & $249(47.3)$ \\
\hline Duration of antibiotics, day & $13.0(7.0-24.0)$ \\
\hline Adjunctive steroid use & $91(17.3)$ \\
\hline Dose (prednisone equivalent), mg & $50.0(25.0-75.0)$ \\
\hline Duration, day & $9.0(3.0-22.5)$ \\
\hline \multicolumn{2}{|l|}{ Appropriateness of initial empiric antibiotics* } \\
\hline Appropriate & $102(48.3)$ \\
\hline Inappropriate & $92(43.6)$ \\
\hline Not applicable & $17(8.1)$ \\
\hline $\begin{array}{l}\text { Changed antibiotics according to } \\
\text { microbiologic results* }\end{array}$ & $135(64.0)$ \\
\hline $\begin{array}{l}\text { Additional ICU admission associated with } \\
\mathrm{HAP} / \mathrm{VAP}^{\dagger}\end{array}$ & $107(28.2)$ \\
\hline ICU length of stay, day & $8.0(3.0-16.0)$ \\
\hline \multicolumn{2}{|l|}{ Organ support during ICU stay } \\
\hline HFNC & $42(39.3)$ \\
\hline Duration, day & $2.0(1.0-5.0)$ \\
\hline Invasive mechanical ventilation & $79(73.8)$ \\
\hline Duration, day & $9.0(4.0-15.8)$ \\
\hline Renal replacement therapy & $26(24.3)$ \\
\hline ECMO & $2(1.9)$ \\
\hline Limitation of life-sustaining treatments & $157(29.8)$ \\
\hline
\end{tabular}

Values are presented as number (\%) or median (interquartile range).

*Data were available for 211 patients with microbiologic diagnosis. ${ }^{\dagger}$ Data were calculated for 379 patients who were diagnosed with HAP/VAP in general wards.

ICU: intensive care unit; HAP: hospital-acquired pneumonia; VAP: ventilator-associated pneumonia; HFNC: high-flow nasal cannula; ECMO: extracorporeal membrane oxygenation. 
domonas aeruginosa species (21.7\%).

\section{Treatment}

An extended-spectrum penicillin/beta-lactamase inhibitor (59.3\%) and respiratory fluoroquinolone (32.1\%) are frequently used as initial empirical antibiotics (Table 4). Combination antibiotic therapy was provided to 249 patients (47.3\%). Thereafter, adjunctive steroids were prescribed to 91 patients (17.3\%). The median prednisone-equivalent dose was 50.0 $\mathrm{mg}$ (range, 25.0-75.0 $\mathrm{mg}$ ), and the median treatment duration was 9.0 days (range, $3.0-22.5$ days).

We diagnosed microbiological, clinical, and other possible infections in 211 (40.1\%), 303 (57.6\%), and 12 (2.3\%) patients, respectively. Among the 211 patients with microbiological infections, an appropriate empirical antibiotic regimen was provided in $48.3 \%$ of the cases. Based on the susceptibility test, the antibiotics were changed in 135 patients (64.0\%).

Among the 379 patients who were diagnosed with HAP in general wards, 107 patients (28.2\%) were admitted to the ICU. The median length of stay in the ICU was 8.0 days (range, 3.016.0 days). During the ICU stay, 42 patients (39.3\%) received high-flow nasal cannula therapy, while 79 patients (73.8\%) received invasive MV. Extracorporeal membrane oxygenation

Table 5. Clinical outcomes of patients with hospitalacquired and ventilator-associated pneumonia

\begin{tabular}{|lc|}
\hline \multicolumn{1}{|c|}{ Variable } & Value (n=526) \\
\hline Clinical responses & \\
\hline Clinical cure & $174(65.4)$ \\
\hline Clinical failure & $11(2.1)$ \\
\hline Recurrence & \\
\hline Microbiological responses* & $106(57.9)$ \\
\hline Microbiological eradication & $23(12.6)$ \\
\hline Colonization & $50(27.3)$ \\
\hline Microbiological failure & $4(2.2)$ \\
\hline Microbiological recurrence & $30(18-53)$ \\
\hline Hospital length of stay, day & $378(71.9)$ \\
\hline Hospital survivor & \\
\hline Destination & $205(54.2)$ \\
\hline Home & $173(45.8)$ \\
\hline Transfer & 158 \\
\hline Step-down & 15 \\
\hline Step-up & \\
\hline
\end{tabular}

Values are presented as number (\%) or median (interquartile range).

*In 28 of 211 patients, follow-up cultures were not performed, data were available in 183 patients. was performed on two patients (1.9\%).

\section{Response to treatment and clinical outcomes}

Among the total 526 patients, clinical cure, clinical failure, or the recurrence of pneumonia was observed in 344 (65.4\%), $171(32.5 \%)$, and $11(2.1 \%)$ patients, respectively (Table 5). Furthermore, 183 patients were diagnosed with microbiological infections and were treated with follow-up cultures, but microbiological eradication was observed in only 106 (57.9\%) patients.

The hospital mortality rate was $28.1 \%$, and the median length of hospital stay was 30 days (range, 18-53 days). Among the patients who survived and were discharged from the hospital, $54.2 \%$ patients returned to their homes and $45.8 \%$ patients were transferred to other hospitals or similar facilities. Most of the referral cases were transferred to step-down care.

\section{Discussion}

In this study, we evaluated the clinical and microbiological characteristics, disease management, and the clinical outcomes of patients with HAP/VAP in Korea. The incidence of HAP/VAP was found to be 2.54/1,000 patients in Korea, and most patients $(72.1 \%)$ were admitted to the general ward of the hospital. The pathogen involved was identified in 211 patients (40.1\%), and MDR pathogens were detected in $70.4 \%$ of the included cases. An appropriate empirical antibiotic therapy was provided to $48.3 \%$ of the studied cases. Thus, clinical cure and microbiological eradication was observed in $65.4 \%$ and $57.9 \%$ of the studied cases, respectively. The hospital mortality rate was estimated to be $28.1 \%$. Among the 378 patients who survived and were discharged, $54.2 \%$ were sent back home, while $45.8 \%$ were transferred to other hospitals or healthcare facilities.

In previous research studies on HAP/VAP, physicians focused on critically ill patients and patients who received MV. The results were used to develop and extensively implement evidence-based preventive care ${ }^{17}$. By implementing preventable care bundles, physicians could reduce the incidence of VAP and improve patient outcomes. Thus, the overall healthcare costs were reduced with this strategy ${ }^{18,19}$. In recent studies, physicians have diverted their attention to HAP patients that have been admitted to the general ward, that is, the nonICU patients. Davis ${ }^{20}$ analyzed the data from the National Healthcare Safety Network, which is associated with the Centers for Disease Control and Prevention. The data was of patients diagnosed with complete nosocomial pneumonia. The retrospective study was conducted from January 1, 2013 through December 31, 2016. In this study, the total inpatient population was obtained from Pennsylvania acute-care facilities. Among these HAP patients, $60.9 \%$ cases were classified 
as non-ventilator HAP (NV-HAP) and 39.1\% cases were classified as VAP. In this study, it was found that the mortality rates of VAP and NV-HAP cases were similar (22.5\% vs. $20.3 \%$ ) in 2016. Moreover, the total healthcare costs of VAP and NV-HAP cases was also similar in 2016 (\$40,118,681 vs. $\$ 42,259,340)$. In addition, Giuliano et al. ${ }^{21}$ analyzed the 2012 United States National Inpatient Sample dataset and compared NV-HAP patients to patients with community-acquired pneumonia, non-pneumonia, or VAP cases. This study also proved that the total health care costs of NV-HAP cases was higher than that of other patients, with longer lengths of hospital stay and a greater likelihood of death as compared to all the groups, except for patients with VAP. In the present study, we also found that most of the HAP patients were diagnosed in general wards $(72.1 \%)$. This indicates that most patients would be NV-HAPs in Korea. Therefore, physicians now emphasize on paying more attention to NV-HAP patients in general wards.

In this study, the most common pathogens were Acinetobacter baumannii $(\mathrm{n}=68)$ and MDR pathogens, which were documented in $70.4 \%$ of microbiologically confirmed HAP/ VAP patients. The proportion of MDR pathogens involved in our study was higher than those included in recent HAP/ VAP studies, which were conducted in other countries ${ }^{22-24}$. However, this increased proportion of MDR pathogens was in complete agreement with recent studies in Korea, including an epidemiological study of patients with sepsis ${ }^{25}$ and a single-center study of HAP in neurological patients ${ }^{26}$. As MDR pathogens are associated with an initial inadequate antibiotic treatment, the knowledge of local epidemiology is essential for assessing clinical outcomes ${ }^{27,28}$. Therefore, to develop domestic-specific guidance on HAP/VAP treatment, physicians must collect local microbiological data, including the prevalence of MDR pathogens.

For evaluating pathogens, positive blood culture is not usually used because it has a low sensitivity towards HAP/VAP ${ }^{29,30}$. Therefore, the guidelines for managing HAP/VAP recommend that respiratory specimens must be extracted with noninvasive or distal quantitative sampling ${ }^{2,3}$. In the present study, however, respiratory samples were not collected from all the patients. Conversely, blood culture tests were performed on a relatively large number of studied cases. Since the clinical judgment in the diagnosis of HAP/VAP is difficult ${ }^{31}$, careful efforts should be made to detect pneumonia in hospitalized patients with new or progressive parenchymal lung infiltrates in their chest radiograph. In contrast, when clinical findings suggest infection, physicians are compelled to extract respiratory specimens for adequate treatments, which are based on microbiological results.

In this study, the hospital mortality rate was $28.1 \%$, which is lower than the mortality of studies with only VAP cases but higher than that of NV-HAP cases ${ }^{22,24,32}$. This finding may be related to the fact that the median age of patients with HAP/ VAP was 71.0 years in this study. The severity of the disease is strongly associated with increased age and comorbidities that exist in aged patients ${ }^{33}$. In addition, as disability, frailty, and comorbidities are highly prevalent in elderly patients, leading to increased mortality rate ${ }^{34}$. In addition, among the patients who survived and were discharged from the hospital, $45.8 \%$ were transferred to hospitals or other facilities. This indicates that patients who suffered from HAP/VAP may encounter difficulties in returning to their daily lives, even after their survival. Therefore, frailty and comorbidities were highly prevalent in elderly patients, which might have compelled physicians to transfer them to other hospitals after acutely managing their HAP/VAP condition.

Although our study provided information about the prevalence, characteristics, and outcomes of HAP/VAP in Korea, there are several limitations that need to be mentioned. Firstly, given its observational nature, our findings remain prone to various biases. We used a national multicenter design to improve the generalizability of our findings, but there is a potential risk of selection bias. This is because we included only the patients who visited the tertiary or university-affiliated hospitals. Secondly, it is possible that we missed some of the HAP/ VAP cases given that we used the International Classification of Diseases-10 code to screen the eligibility of study participants. Thirdly, this study was designed to evaluate the epidemiological features, and we did not collect the data pertaining to long-term outcomes. Future prospective studies of HAP/ VAP should include a larger number of patients, and they must be followed up for a longer period of time. The results of these studies are needed to define the public health burden and economic impact of HAP.

In summary, the prevalence of HAP/VAP in adult hospitalized patients in Korea was 2.56/1,000 patients. In tertiary hospitals of Korea, patients with HAP/VAP were elderly and had a risk of aspiration. Therefore, they were often referred to stepdown centers after the management of HAP/VAP. Additional epidemiological studies must be conducted and innovative health care policies must be designed to increase the awareness of HAP/VAP in citizens of Korea. With these measures, we can improve the clinical outcomes of those afflicted with HAP/VAP.

\section{Author Affiliations}

${ }^{\mathrm{l}}$ Department of Critical Care Medicine, Samsung Medical Center, Sungkyunkwan University School of Medicine, Seoul, ${ }^{2}$ Division of Pulmonary, Allergy, and Critical Care Medicine, Department of Internal Medicine, Korea University Guro Hospital, Seoul, ${ }^{3}$ Department of Pulmonary and Critical Care Medicine, Asan Medical Center, University of Ulsan College of Medicine, Seoul, ${ }^{4}$ Division of Allergy and Respiratory Medicine, Department of Internal Medicine, Soonchun hyang University Bucheon Hospital, Bucheon, ${ }^{5}$ Department of Inter- 
nal Medicinn, Division of Pulmonology, Allergy and Critical Care Medicine, Busan Paik Hospital, Inje University College of Medicine, Busan, ${ }^{6}$ Division of Pulmonary, Allergy and Critical Care Medicine, Department of Internal Medicine, Pusan National University Yangsan Hospital, Yangsan, ${ }^{7}$ Department of Internal Medicine, Jeju National University Hospital, Jeju National University School of Medicine, Jeju, ${ }^{8}$ Division of Pulmonary and Critical Care Medicine, Department of Internal Medicine, Inje University Sanggye Paik Hospital, Seoul, ${ }^{9}$ Division of Pulmonary and Critical Care Medicine, Department of Internal Medicine, Ilsan Paik Hospital, Inje University College of Medicine, Goyang, ${ }^{10}$ Department of Internal Medicine, Research Center for Pulmonary Disorders, Jeonbuk National University Medical School, Jeonju, ${ }^{11}$ Department of Internal Medicine, Ulsan University Hospital, Ulsan, ${ }^{12}$ Department of Pulmonary and Critical Care Medicine, Chungnam National University Hospital, Daejeon, ${ }^{13}$ Division of Pulmonary, Allergy, and Critical Care Medicine, Department of Internal Medicine, Konkuk University School of Medicine, Seoul, ${ }^{14}$ Division of Pulmonary and Critical Care Medicine, Department of Medicine, Samsung Medical Center, Sungkyunkwan University School of Medicine, Seoul, Republic of Korea

\section{Authors' Contributions}

Conceptualization: Jeon K. Methodology: Ko RE, Min KH, Jeon K. Formal analysis: Ko RE, Min KH, Jeon K. Data curation: Hong SB, Baek AR, Lee HK, Cho WH, Kim C, Chang Y, Lee SS, Oh JY, Lee HB, Bae S, Monn JY, Yoo KH, Jeon K. Software: Ko RE, Min KH. Investigation: Ko RE, Min KH, Hong SB, Baek AR, Lee HK, Cho WH, Kim C, Chang Y, Lee SS, Oh JY, Lee HB, Bae S, Moon JY, Yoo KH, Jeon K. Writing-original draft preparation: Ko RE, Min KH, Jeon K. Writing-review and editing: Ko RE, Min KH, Hong SB, Baek AR, Lee HK, Cho WH, Kim C, Chang Y, Lee SS, Oh JY, Lee HB, Bae S, Moon JY, Yoo KH, Jeon K. Approval of final manuscript: all authors.

\section{Conflicts of Interest}

No potential conflict of interest relevant to this article was reported.

\section{Funding}

This study was funded by the 2019 Research Grant (2019E2808-00), which was received from the Korean Disease Control and Prevention Agency.

\section{References}

1. American Thoracic Society; Infectious Diseases Society of America. Guidelines for the management of adults with hospital-acquired, ventilator-associated, and healthcare-associated pneumonia. Am J Respir Crit Care Med 2005;171:388416.

2. Kalil AC, Metersky ML, Klompas M, Muscedere J, Sweeney DA, Palmer LB, et al. Management of adults with hospitalacquired and ventilator-associated pneumonia: 2016 Clinical Practice Guidelines by the Infectious Diseases Society of America and the American Thoracic Society. Clin Infect Dis 2016;63:e61-111.

3. Torres A, Niederman MS, Chastre J, Ewig S, FernandezVandellos P, Hanberger H, et al. International ERS/ESICM/ ESCMID/ALAT guidelines for the management of hospitalacquired pneumonia and ventilator-associated pneumonia: guidelines for the management of hospital-acquired pneumonia (HAP)/ventilator-associated pneumonia (VAP) of the European Respiratory Society (ERS), European Society of Intensive Care Medicine (ESICM), European Society of Clinical Microbiology and Infectious Diseases (ESCMID) and Asociacion Latinoamericana del Torax (ALAT). Eur Respir J 2017;50:1700582.

4. Eber MR, Laxminarayan R, Perencevich EN, Malani A. Clinical and economic outcomes attributable to health care-associated sepsis and pneumonia. Arch Intern Med 2010;170:34753.

5. Park H, Adeyemi AO, Rascati KL. Direct medical costs and utilization of health care services to treat pneumonia in the United States: an analysis of the 2007-2011 Medical Expenditure Panel Survey. Clin Ther 2015;37:1466-76.

6. Sopena N, Sabria M, Neunos Study G. Multicenter study of hospital-acquired pneumonia in non-ICU patients. Chest 2005;127:213-9.

7. Magill SS, Edwards JR, Bamberg W, Beldavs ZG, Dumyati G, Kainer MA, et al. Multistate point-prevalence survey of health care-associated infections. N Engl J Med 2014;370:1198-208.

8. Cakir Edis E, Hatipoglu ON, Yilmam I, Eker A, Tansel O, Sut N. Hospital-acquired pneumonia developed in non-intensive care units. Respiration 2009;78:416-22.

9. Sopena N, Heras E, Casas I, Bechini J, Guasch I, Pedro-Botet ML, et al. Risk factors for hospital-acquired pneumonia outside the intensive care unit: a case-control study. Am J Infect Control 2014;42:38-42.

10. Everts RJ, Murdoch DR, Chambers ST, Town GI, Withington SG, Martin IR, et al. Nosocomial pneumonia in adult general medical and surgical patients at Christchurch Hospital. N Z Med J 2000;113:221-4.

11. Chawla R. Epidemiology, etiology, and diagnosis of hospitalacquired pneumonia and ventilator-associated pneumonia in Asian countries. Am J Infect Control 2008;36(4 Suppl):S93-100. 
12. Magiorakos AP, Srinivasan A, Carey RB, Carmeli Y, Falagas ME, Giske CG, et al. Multidrug-resistant, extensively drugresistant and pandrug-resistant bacteria: an international expert proposal for interim standard definitions for acquired resistance. Clin Microbiol Infect 2012;18:268-81.

13. Vincent JL, Moreno R, Takala J, Willatts S, De Mendonca A, Bruining H, et al. The SOFA (Sepsis-related Organ Failure Assessment) score to describe organ dysfunction/failure. On behalf of the Working Group on Sepsis-Related Problems of the European Society of Intensive Care Medicine. Intensive Care Med 1996;22:707-10.

14. Rhodes A, Evans LE, Alhazzani W, Levy MM, Antonelli M, Ferrer R, et al. Surviving Sepsis Campaign: international guidelines for management of sepsis and septic shock: 2016. Intensive Care Med 2017;43:304-77.

15. Mandell LA, Niederman MS. Aspiration pneumonia. N Engl J Med 2019;380:651-63.

16. Singer M, Deutschman CS, Seymour CW, Shankar-Hari M, Annane D, Bauer M, et al. The Third International Consensus Definitions for Sepsis and Septic Shock (Sepsis-3). JAMA 2016;315:801-10.

17. Morris AC, Hay AW, Swann DG, Everingham K, McCulloch C, McNulty J, et al. Reducing ventilator-associated pneumonia in intensive care: impact of implementing a care bundle. Crit Care Med 2011;39:2218-24.

18. Klompas M, Branson R, Eichenwald EC, Greene LR, Howell MD, Lee G, et al. Strategies to prevent ventilator-associated pneumonia in acute care hospitals: 2014 update. Infect Control Hosp Epidemiol 2014;35 Suppl 2:S133-54.

19. Khan R, Al-Dorzi HM, Al-Attas K, Ahmed FW, Marini AM, Mundekkadan S, et al. The impact of implementing multifaceted interventions on the prevention of ventilator-associated pneumonia. Am J Infect Control 2016;44:320-6.

20. Davis J. A second breadth: hospital-acquired pneumonia in Pennsylvania, nonventilated versus ventilated patients [Internet]. Harrisburg, PA: Pennsylvania Patient Safety Advisory; 2018 [cited 2020 Dec 10]. Available from: http://patientsafety. pa.gov/ADVISORIES/documents/201809_home.pdf.

21. Giuliano KK, Baker D, Quinn B. The epidemiology of nonventilator hospital-acquired pneumonia in the United States. Am J Infect Control 2018;46:322-7.

22. Micek ST, Chew B, Hampton N, Kollef MH. A case-control study assessing the impact of nonventilated hospital-acquired pneumonia on patient outcomes. Chest 2016;150:1008-14.

23. Martin-Loeches I, Deja M, Koulenti D, Dimopoulos G, Marsh
B, Torres A, et al. Potentially resistant microorganisms in intubated patients with hospital-acquired pneumonia: the interaction of ecology, shock and risk factors. Intensive Care Med 2013;39:672-81.

24. Ibn Saied W, Mourvillier B, Cohen Y, Ruckly S, Reignier J, Marcotte G, et al. A comparison of the mortality risk associated with ventilator-acquired bacterial pneumonia and nonventilator ICU-acquired bacterial pneumonia. Crit Care Med 2019;47:345-52.

25. Jeon K, Na SJ, Oh DK, Park S, Choi EY, Kim SC, et al. Characteristics, management and clinical outcomes of patients with sepsis: a multicenter cohort study in Korea. Acute Crit Care 2019;34:179-91.

26. Lee HS, Moon J, Shin HR, Ahn SJ, Kim TJ, Jun JS, et al. Pneumonia in hospitalized neurologic patients: trends in pathogen distribution and antibiotic susceptibility. Antimicrob Resist Infect Control 2019;8:25.

27. Beardsley JR, Williamson JC, Johnson JW, Ohl CA, Karchmer TB, Bowton DL. Using local microbiologic data to develop institution-specific guidelines for the treatment of hospitalacquired pneumonia. Chest 2006;130:787-93.

28. Zilberberg MD, Shorr AF, Micek ST, Vazquez-Guillamet C, Kollef MH. Multi-drug resistance, inappropriate initial antibiotic therapy and mortality in Gram-negative severe sepsis and septic shock: a retrospective cohort study. Crit Care 2014; 18:596.

29. Luna CM, Videla A, Mattera J, Vay C, Famiglietti A, Vujacich $\mathrm{P}$, et al. Blood cultures have limited value in predicting severity of illness and as a diagnostic tool in ventilator-associated pneumonia. Chest 1999;116:1075-84.

30. Rello J, Mirelis B, Alonso C, Prats G. Lack of usefulness of blood cultures to diagnose ventilator-associated pneumonia. Eur Respir J 1991;4:1020.

31. Fagon JY, Chastre J, Hance AJ, Domart Y, Trouillet JL, Gibert C. Evaluation of clinical judgment in the identification and treatment of nosocomial pneumonia in ventilated patients. Chest 1993;103:547-53.

32. Koulenti D, Tsigou E, Rello J. Nosocomial pneumonia in 27 ICUs in Europe: perspectives from the EU-VAP/CAP study. Eur J Clin Microbiol Infect Dis 2017;36:1999-2006.

33. Heuser MD, Case LD, Ettinger WH. Mortality in intensive care patients with respiratory disease. Is age important? Arch Intern Med 1992;152:1683-8.

34. Janssens JP, Krause KH. Pneumonia in the very old. Lancet Infect Dis 2004;4:112-24. 